\title{
Quality control of constructions: European trends and developments
}

\author{
Frits Meijer and Henk Visscher \\ OTB Research Institute for the Built Environment, \\ Delft University of Technology, Delft, The Netherlands
}

\section{Quality control of constructions}

Received 6 February 2017 Revised 4 May 2017 Accepted 7 May 2017

\begin{abstract}
Purpose - This paper aims to evaluate the quality control systems for constructions in seven countries in Europe with the purpose to trace innovative approaches and best practices that can serve as examples for other countries.

Design/methodology/approach - The paper is based on a series of research projects carried out over a number of years. The research results were updated in 2016 with a desktop research project in seven European countries. The results from this latest project form the heart of this paper. The information is organised into tables that describe and analyse the main features of the quality control systems of the countries (e.g. scope, focus and main characteristics of the procedures and quality demands on building professionals).

Findings - Several similar trends can be recognised in the quality control systems of the various European Union (EU) countries. Quality control is getting more and more privatised and the control framework is setting checks and balances throughout the construction process. Other findings are that scope and focus of the statutory control is unbalanced. Within the control processes emphasis is put on the safety aspects of complex constructions. Far fewer demands are made on the quality of the builders. Re-orientation of the building regulatory framework seems to be needed.

Research limitations/implications - The paper only focusses on European countries where private quality control is established and on selected topics. The findings are based on desktop research and not on the practical experiences of the stakeholders involved in the countries studied.

Practical implications - The paper draws some important recommendations for policymakers in the building regulatory field. It suggests both an enhancement of the effectiveness of the quality control procedure as well as the commitment of builders to comply with the regulations.

Social implications - The quality of constructions is essential for the wellbeing and safety of its users, its occupants or its visitors. This applies to the whole range of quality aspects: structural- and fire safety, health, sustainability and usability aspects. The analyses and recommendations of this paper aim to contribute to an improvement of the overall construction quality.

Originality/value - The paper makes an original contribution to the (limited) literature that is available in this field. The results can be used to situate the quality control systems of each member state within the EU, to assess the main trends, and it can be used as a guide to develop strategic choices on possible improvements in each country.
\end{abstract}

Keywords Sustainability, European Union, Quality control, Privatisation, Building regulations, Construction quality

Paper type Research paper

(C) Frits Meijer and Henk Visscher. Published by Emerald Publishing Limited. This article is published under the Creative Commons Attribution (CC BY 4.0) licence. Anyone may reproduce, distribute, translate and create derivative works of this article (for both commercial and noncommercial purposes), subject to full attribution to the original publication and authors. The full terms of this licence may be seen at http://creativecommons.org/licences/by/4.0/legalcode

The authors would like to acknowledge the helpful comments from the reviewers.



$$
\begin{array}{r}
\text { International Journal of Law in the } \\
\text { Built Environment } \\
\text { Vol. } 9 \text { No. } 2,2017 \\
\text { pp. 143-161 } \\
\text { Emerald Publishing Limited } \\
1756-1450 \\
\text { DOI } 10.1108 / \text { IJLBE-02-2017-0003 }
\end{array}
$$




\section{IJLBE \\ 9,2}

\section{Introduction}

Starting point of this paper is recent building regulatory developments in The Netherlands. From the late 90 s of the twentieth century, successive Dutch Governments have been trying to minimise the building regulatory burden and to privatise the quality control of constructions. These attempts have only been partly successful. Some technical requirements have been withdrawn from the regulations, and the number of constructions that are exempt from quality control has been enlarged substantially (Meijer and Visscher, 1998, 2006, 2016; Costa Branco et al., 2011). In the same period, however, new requirements on energy and sustainable performance have been incorporated in the building regulations. These requirements have been tightened regularly since then (Beerepoot, 2007). During the past decade, discussions to fundamentally change the quality control system continued (Meijer and Visscher, 2016). The dominant policy line of subsequent governments has been "privatise if possible and keep it public when necessary". Eventually, this has led to a new bill on Quality Assurance of Buildings that was introduced in May 2016 into parliament (MBZK Ministerie van Binnenlandse Zaken en Koninkrijksrelaties/Ministry of Interior and Kingdom Relations, 2015). The final implementation is still under debate in parliament. When adopted, this law will change quality control of constructions in The Netherlands fundamentally. The control on compliance with the technical requirements will be transferred from public authorities to private parties. According to the policymakers, these changes will have a general positive effect on the quality of the building stock. Besides that, it will also streamline the building processes and diminish the administrative burden on all parties. This paper puts the current Dutch policy plans in a broader European framework and places them within the main trends that have changed systems of quality control in European countries in the past two decades. The paper is based on a series of research projects on building regulatory systems carried out by the authors from the mid-90s on. The research questions and research themes addressed in these projects have been consistent throughout these years. To name the most important ones: For what subjects minimum quality demands are set? How are these demands formulated? Does the procedure make a distinction in categories of construction works? How are permit procedures organised? What tasks and responsibilities do public and private parties have with regard to permit procedures and enforcement? These questions were answered in 1993 in 5 European countries), in 1997 (7 countries), 2002 (8 countries), 2009 (all European Union [EU] countries), 2015 (14 countries) and 2016 (7 countries). In all research projects, relevant policy reports were analysed, such as the building regulations, technical documents, manuals and guidance's to interpret the regulations or the enforcement procedures). Additionally, interviews were held with stakeholders in the various countries. In some projects, national specialists answered specific questionnaires (e.g. 2009 and 2015). The state-of-the-art description of the systems is mainly based on the 2016 project. In our most recent European comparative research project commissioned by the Dutch Government, quality control in England \& Wales, Ireland, Germany, France, Norway and Sweden were compared and analysed (Meijer and Visscher, 2016). In these selected countries, private building control already has been established within the regulatory framework. The insights into trends and developments of the quality control systems are based on all studies mentioned. This paper provides original and new insights into the matter. This applies to both the analyses of the current situation as the analyses of the main trends.

This paper sketches the state-of-the-art of quality control systems for constructions in Europe and places the insights into a wider perspective. The goal of the paper is not only to explore to what extent current statutory quality control systems provide sufficient assurance that constructions meet the minimum demands set in the building regulations, it 
also traces approaches in one country that can serve as examples for other countries. The paper is structured along seven sections. Section 2 sketches the overall framework by highlighting overall recent trends and developments relating to building control in Europe. The sections that follow are based on the research mentioned above. Section 3 addresses the scope of the regulations. The focus and organisation of quality control procedures are discussed in Section 4. Section 5 deals with the regulatory demands that are made on the inspections during the construction phase. The question to what extent quality demands are made on the quality controllers and other building professional is addressed in Section 6 . Section 7 summarises the main conclusions and gives recommendations to improve the quality control system. These recommendations are focussed on the enhancement of both the effectiveness of the quality control procedure as well as the commitment of builders to comply with the regulations.

\section{Deregulation and privatisation of European quality control systems}

On the basis of a range of international comparative studies in European countries, several closely related and sometimes conflicting "building regulatory development trends" can be identified.

Climate change and the need to reduce energy use and emissions have urged policymakers to strengthen and expand the demands on sustainable quality (e.g. on energy performance and insulation values; Visscher et al., 2016). Nowadays, all European countries have included these sustainable demands in their building regulations. The influence of European policies and Directives on this development is clearly noticeable (Meijer and Visscher, 2016).

The second development is the persistent wish of governments to diminish the regulatory pressure of the building regulations on the building industry. As in The Netherlands, during the past decades, this deregulation effort has also had a prominent place on the political agenda of most governments in other European countries. The results of these policies have manifested themselves in different ways. Building permit procedures were streamlined and simplified. Requirements were simply removed from the regulations. A growing number of constructions were placed outside the statutory quality control processes. Either by making them exempt from control or by including them in a less burdensome notification procedure (Costa Branco et al., 2011; Meijer and Visscher, 1998, 2006, 2016; Ecorys and Delft University of Technology, 2016).

The third important development in the past decades has been that private parties have gained an important role in the quality control process of constructions (Meijer and Visscher, 1998, 2006, 2016). This development is related with the before-mentioned deregulation trend. By sourcing out control to private parties that are already involved in the construction process, the quality control process can be streamlined. This development has gone hand-in-hand with emerging new certification and recognition systems within the building industry to guard the quality of private controllers and sometimes building professionals in general. These systems should guarantee that these professionals fulfil their responsibilities in an adequate way. Consequently, government involvement in the quality control process of construction work has been diminished. In most countries (local), authorities still are responsible for the check of zoning issues, but their involvement in the control of the technical quality is diminishing rapidly.

The next sections describe and analyse the current quality control systems in frontrunner countries in Europe. 
IJLBE

9,2

146

Figure 1.

Scope of the building regulations in seven European countries

\section{Scope of quality control procedures}

The general rule in all countries is that all constructions have to meet the requirements set in the building regulations. These requirements demand for a range of issues (from fire safety to sustainability) and building components (e.g. stairs, windows and ceiling height) a minimum quality level. All constructions must meet these minimum demands. However, in practice, most constructions are not (fully) processed through the statutory quality control procedure. In practice, only complex constructions are eligible for a full quality control procedure (see Figure 1). Besides that, all countries have a list of exemptions and constructions that can be notified to the authorities. Figure 1 sums up the different categories of constructions.

In general, minor alterations and renovation projects, extensions, annexes, garden sheds and similar activities are exempted from quality control. In addition, every country has a category of construction works that must be notified to the building-control authorities but will not be inspected in a comprehensive way. In most countries, the criteria that define whether a construction is notifiable or not are not crystal clear. However, they all are related to the width, length and height of a construction (volume or floor area), its use and its location and the distance to neighbouring properties. In general, this means that minor construction works, for which safety, health and location-dependent requirements play no significant role, can be notified.

The categorisation of constructions is generally based on a risk analyses. Variables that play a role are the complexity of the construction, the risk of failure of the construction and

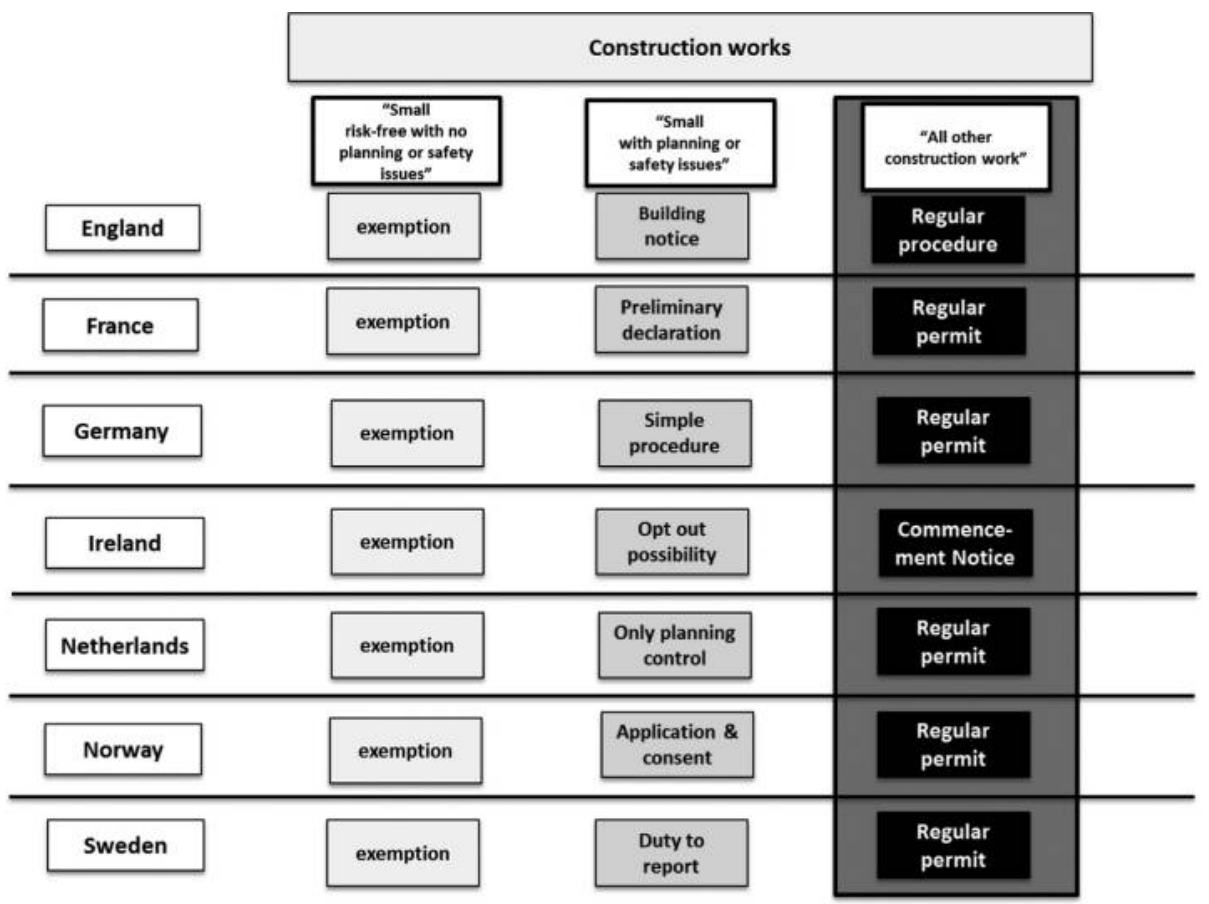

Source: Meijer and Visscher (2016) 
the seriousness and scale of the subsequent consequences. The exact contents and weight of these criteria is also generally unknown. It can be assumed though that the categorisation in most countries is similar to the EU system of consequence classes for structural safety for the Eurocodes. In these Eurocodes, a distinction is made between three consequences classes, considering the building type, occupancy and size. Nonetheless, the building regulations in the various countries are generally not very explicit about this. However, some countries provide more clarity. For instance, the Norwegian building regulations classify constructions that need a building permit in three classes. The classification is

\section{Quality control of constructions}

147 based on the complexity of the structure, the difficulty to build it and the consequences that may occur if something goes wrong with the construction (Berge, 2003). Class 1 contains simple structures where errors would have minor consequences. Class 2 contains constructions with a small degree of difficulty where errors would have medium consequences and constructions with a medium degree of difficulty and minor to medium consequences (e.g. apartment buildings). Class 3 contains constructions with a medium degree of difficulty where errors would have serious consequences and constructions that have a large degree of difficulty where errors could have minor, medium or large consequences. The regulations do not define precisely which constructions are categorised in which class. The proposed new system of The Netherlands is roughly based on the same principle. The category of exemptions (small constructions with no structural consequences) will have to meet certain clearly defined zoning criteria (e.g. height, floor area and location). Small constructions that do not meet these zoning criteria need a permit. They are still exempt from the technical quality control but have to be checked against planning requirements. It is expected that roughly 60 per cent of all constructions that currently need a building permit in the future will be exempt from the check if they meet the technical requirements. All other constructions are categorised into three classes based on the consequences that can occur when something goes wrong with the construction (MBZK Ministerie van Binnenlandse Zaken en Koninkrijksrelaties/Ministry of Interior and Kingdom Relations, 2015). The division is based on two criteria that determine the direct impact on users in the event of failure of a structure: structural safety; and fire safety. Consequence class 1 contains constructions with a low risk (structural renovations, single family dwellings and small industrial or agricultural buildings). In Class 3 , the constructions with a high consequence are placed (such as hospitals and residential buildings higher than 70 meters). The nature of the quality control depends on the classification.

All in all, the conclusion can be drawn that the categorisation pictured in Figure 1 follows the same lines in all the countries studied. There are no remarkable or substantial differences with respect to the contents of the three categories. Although the structure and contents of the categorisation is comparable, the contents of the criteria used in the various to determine whether a construction is exempt or must follow a notification procedure differ. The only similarity is that all criteria are related with the spatial characteristics and use of the constructions. A general trend during the past decades has been that the list of exemptions and works that have to be notified has grown. This means that European countries show a tendency to extend the number of constructions that fall outside the quality control regime.

\section{Main characteristics of the regular quality control procedure}

Figure 2 summarises the main characteristics of the regular quality control procedure for constructions in the seven European countries. The figure pictures the statutory quality control procedures to check whether the technical demands set in the building regulations are being met. The checks on the planning, zoning and aesthetics requirements are not 


\section{IJLBE \\ 9,2}

\section{8}

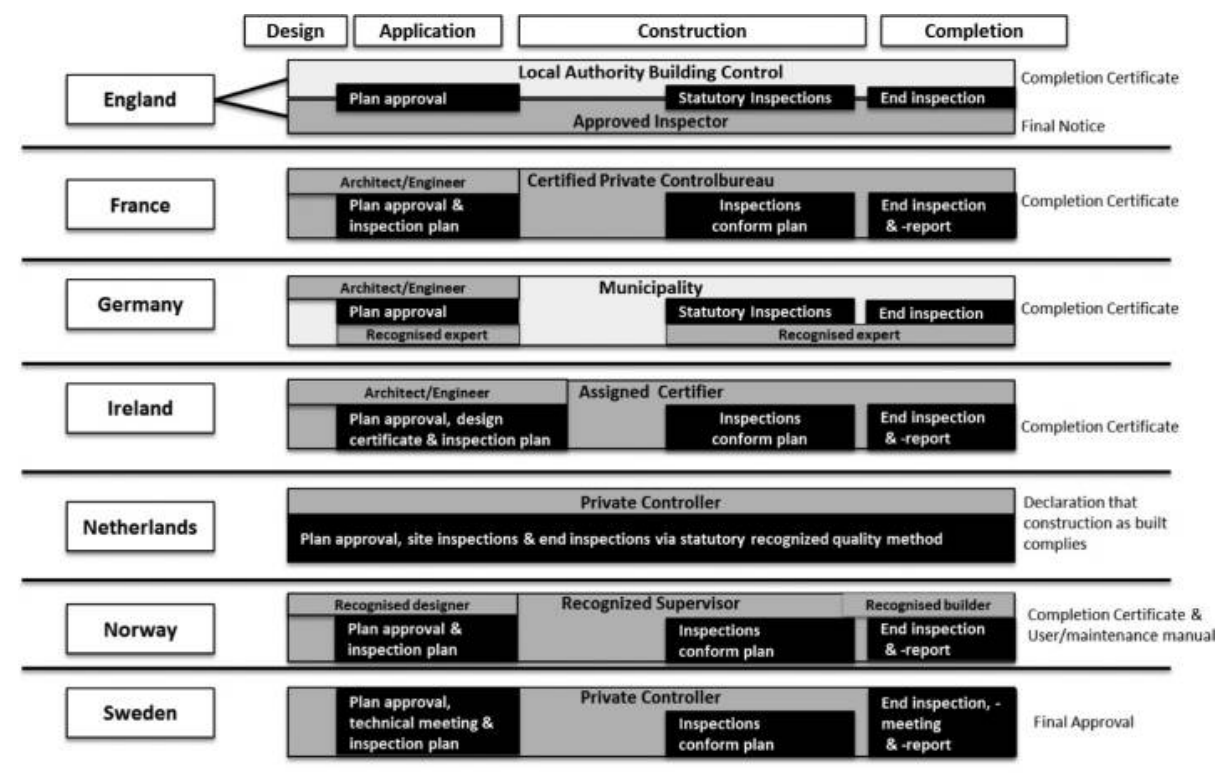

Source: Meijer and Visscher, 2016

Figure 2.

Main characteristics of the regular quality control procedure in seven European countries

included. In all countries (local), authorities are responsible for these planning approval procedures.

Figure 2 makes distinction between the phases of the construction process:

- starting with the design phase; and

- ending with the completion of the construction.

The central part of the figure gives an overview of the legal quality control procedures and parties responsible. A grey colour means that private building professionals are involved and responsible; white indicates local authority involvement. The black rectangles show obligatory elements within the quality control procedures. Looking at Figure 2, issues are clearly distinguishable with regard to the organisation and structure of the quality control procedure. They are discussed below.

\subsection{Private controllers play an important role in the quality control process}

In the first place, it is noticeable that private parties play a dominant role in the regular quality control procedure. This starts with the role of the architect in the designing phase. From the earliest days of architecture on the architects' role in construction has been influenced and framed by rules, regulations, standards and governance guidance's. Imrie and Street (2009, 2011) have elaborately explored the tensions, contradictions and interrelation between building regulations, construction practices and the roles and responsibilities architects. Within the EU legislation on mutual recognitions of qualifications, architecture was one of the first building professions that were regulated. To qualify for recognition, a candidate must have studied architecture at a certain university or institution with a required minimum study length. The main purpose of this legislation is to 
safeguard the freedom of movement of architects within the EU, and to guarantee that architects from the different member states have the same basic skills and competences. Figure 2 shows, however, that there is a wide variety regarding the architects' role in the quality control systems in the various European countries. France, Germany and Ireland have granted to architects the power to submit construction-related documents to local authority building control (e.g. application for building permits or design approvals). In most cases, this is not confined to submitting the design or construction plan, but extents also to documents that relate to, for instance, environmental, energy and fire safety issues. In Germany and France, the quality control and inspection role of these issues over recent years has been devolved away from local authority building control and is becoming the increasing responsibility of architects. Recently, Ireland introduced the requirement that a qualified professional, either an architect or engineer, must sign compliance certification both at the design as the completion phase. In Norway, the profession is semi-regulated. The practicing firms are subject to approval by the authorities, according to their competence, to be eligible to sign on the building permit papers. In The Netherlands and the UK, the title of architect is protected. In Sweden, neither the title nor the profession is protected.

With respect to public versus private control, the countries also show some variety. In England and Wales, an applicant can choose between quality control by a local authority or by a private Approved Inspector. In Germany, local authorities play an important role in the quality control process. The German model can be considered as a mix between public and private quality control. Local authorities are formally responsible for quality control and issuing permits. Recognised building professionals, however, also play an important role in the German system. In the other countries' studies, private parties play an essential role in the process. This can be partly explained by the fact that for the selection of these countries, private involvement was one of the criteria. Other studies, however, show the same trend: private parties are replacing local authority building control (Costa Branco et al., 2011; Meijer and Visscher, 1998, 2006; World Bank Group, 2013; Deman, 2013). One could say that throughout Europe, quality control of constructions is increasingly being privatised.

\subsection{Control activities are distributed evenly during the construction process}

A second important observation (see the black rectangles) is that all countries have developed systems where the checks and balances are evenly distributed throughout the building process. Every country has set demands on the way plan approval should be carried out. Figure 2 shows that sometimes registered architects must be involved or meetings have to be arranged and inspection plans must be made. Site inspections are obligatory during construction. Sometimes reference is made to the inspection plans; sometimes certain construction moments or construction elements are mentioned. The quality control procedure ends in all countries with an end inspection. Constructions can only be taken in to use when a completion certificate (or final approval) has been issued. A short overview per country:

- In England and Wales, local authority building control has to give building approval and issues a completion certificate at the end of the procedure. Approved Inspectors have to submit an initial notice to the local authority at the beginning of the process and submit a final notice at the end of the construction phase (Meijer and Visscher, 2016).

- Complex construction works in France with a higher risk must be controlled by private organisations. This starts during plan approval and continues until completion. Before construction starts, an initial technical report and an inspection 
IJLBE

9,2

150

plan have to be drawn up. After completion, the private controller has to deliver an end report on the technical control. Public and high-rise buildings must have a user permit before they can be used (MLHD Ministère du Logement et de l'Habitat Durable, 2016).

- In the regular procedure of Germany, the application must be signed by an architect or an engineer. Usually, a state recognised expert verifies compliance with the technical requirements. During construction, building control is exercised by the local authority and a site manager appointed by the applicant. Local authorities usually delegate site inspections on structural stability to a state recognised expert. At completion, the local authority issues a completion certificate (Meijer and Visscher, 2016).

- In the relatively new Irish system, competent private building professionals are responsible for the quality control of constructions. Applicants for building approval must submit a Commencement Notice. Besides the inclusion of a certificate of design compliance, proof must be delivered that an Assigned Certifier has been hired in to inspect and certify the works and a builder has been assigned to carry out the works. The Commencement Notice must be accompanied by an inspection notification framework and an inspection plan. After completion of the project, both certifier as builder must certify the completed construction complies with the regulations (DECLG Department of the Environment, Community and Local Government, 2014).

- In the proposed new Dutch system, private parties will be responsible for the technical control of construction works. An independent Admission Organisation is going to assess and certify these private controllers and their control instruments. Local authorities stay responsible for checking planning issues. The applicant has to notify the authorities about the construction plan and the way quality control is taken care off. At the end of the process, the quality controller declares that the building meets the technical demands (IBK Instituut voor Bouwkwaliteit/Institute for Building Quality 2014).

- In Norway, all possible roles (applicant, designer, engineer, builder and controller) must be filled in properly before local authority issues a building permission (DiBK Direktoratet for ByggKvalitet, 2016). The process starts with an obligatory preliminary consultation meeting where the parties involved decide about an inspection plan. This inspection plan is used during the construction and completion phase. At the end of the process, the controller must deliver a completion report and file an application for a completion certificate.

- In Sweden, it is obligatory to make an inspection plan and to organise a technical meeting with all parties involved. The local authority issues a permit once they are satisfied with the inspection plan. An independent quality controller has to take care of inspections. After completion, an end meeting is held, and if the local authority is satisfied, a written notice is issued to the applicant.

All in all, the European quality control procedures seem to be well organised on paper. The checks and balances seem to make it reasonable certain that at the moment a "regular" construction is completed it complies with the technical requirements. However, it is not known how the quality control procedure works out in practice. Besides that, only a part of all constructions are required to undergo this regular procedure. 


\section{Focus on control of safety requirements and complex constructions}

The research project also looked at the regulatory demands that are made on the inspections during the construction phase. The research results show that there are hardly demands made on the nature, contents and depth of inspections (Meijer and Visscher, 2016). Nonetheless, some countries have developed guidelines that quality controllers can use. In England and Wales, public and private controllers have voluntarily committed themselves to the Building Control Performance Standards. These standards give guidelines how qualitative good building control should be performed (DCLG Department for Communities and Local Government, 2014).

The few legal obligations that are in place in the countries focus on structural and fire safety regulations. This especially applies to the quality control of complex constructions (Meijer and Visscher, 2016). The French regulations state, for instance, that private controllers are legally liable to control the structural safety and the safety of persons. One-off or single-family dwellings are hardly or only roughly controlled. In Germany, the state recognised expert focusses on the control of the structural elements. Usually, only the fire safety and structural stability requirements are checked. In Norway, independent private control is obligatory for critical building elements (e.g. structural components, fire safety and the building envelope). Throughout Europe, site inspections tend to have a random character. Nonetheless, usually control takes place when certain (critical) construction phases are finished.

There are relatively very few legal requirements concerning the nature, contents and depth of the control of "sustainable" (e.g. demands on energy performance and material use) and usability requirements. This also applies to the inspection of simpler constructions (e.g. newly built dwellings, renovation activities and extensions). The fact that sustainability issues tend to have a lesser importance than safety issues is also confirmed by Meacham (2016). One of his conclusions (based on a study of 12 countries) is that sustainable issues do not receive the same level of attention as health and safety. In view of the growing political attention for the energy performance of the housing stock, it is foreseeable that this is going to change in the near future. The EU (and its Member States) has set ambitious energysaving targets for the near future. The energy efficiency demands within the building regulations are expected to play a key role in meeting these energy-saving goals. In this respect, the study of Rosenow et al. (2016) is interesting. On the basis of an empirical analysis of current policy mixes in buildings energy efficiency in $14 \mathrm{EU}$ countries, the study gives an interesting (although first) insight into how buildings policy mixes could be made more effective.

\section{Quality demands on building professionals}

The previous section pointed out that only a part of the constructions that are subject to quality control are controlled in practice. This makes the role of the builders and installers an important one. This section focusses on quality demands that are made on builders and installers. A distinction is made between demands on private quality controllers (paragraph 6.1) and demands on builders and installers (paragraph 6.2).

\subsection{Private controllers}

In all countries, private controllers have to be certified, recognised or approved. In England and Wales, Approved Inspectors must be certified and registered before they can act. Private control organisations in France have to be certified and accredited. French organisations can be certified for various control scopes (e.g. all regulations, only fire safety regulations or regulations for installations). In Germany, recognised or registered building 
IJLBE

9,2

Figure 3.

Supervision of private controllers in European countries professionals play an important role in the system. As stated before, registered architects/ engineers must submit the application and they usually take care of plan approval. In addition - depending of the construction type and control scope - state recognised experts must be involved in the quality control process. They can be called in by both applicants as local authorities. For the Irish, building professionals inclusion on statutory registers is the primary means of establishing competency. The registers for architects and engineers are in operation; for builders, it should be in place shortly. In the proposed new Dutch system, an independent organisation is going to assess and certify private quality controllers and their control instruments. This Dutch system differs completely from the other countries because focus is placed on recognising quality control methods and not directly on the building professionals. For regular construction works in Norway, all parties involved (applicants, designers, engineers and builders) must be approved by the central government as a responsible enterprise (KoRD Kommunal og Regionaldepartemente/Ministry of Local Government and Regional Development, Housing and building department, 2010). The general rule in Sweden is that for a work needing building approval, there must be at least one private person/party involved that controls the quality during construction. The private quality controllers must be certified before they can operate in practice (Meijer and Visscher, 2016).

Certification, recognition or approval of private controllers implies that they are registered and controlled by supervising bodies. Three types of supervision (see Figure 3) can be distinguished in the various countries, namely, supervision by the following:

(1) Professional organisations or bodies (England, Ireland and Germany).

(2) National Accreditation Organisations (France and Sweden).

(3) Governmental organisations (Norway and in the proposed new system in The Netherlands).

\begin{tabular}{|c|c|c|}
\hline England & Approved Inspectors & Accreditation and supervision by Construction Industry Council \\
\hline France & Private control bureaus & Certification and supervision by National Accreditation Body COFRAC \\
\hline Germany & $\begin{array}{l}\text { Architects, engineers } \\
\text { and recognized experts }\end{array}$ & Registration and supervision by Professional organisations/bodies \\
\hline Ireland & Assigned certifiers & Registration and supervision by Professional organisations/bodies \\
\hline Netherlands & $\begin{array}{l}\text { Quality control } \\
\text { instrument }\end{array}$ & Recognition and supervision by National Admittance Organisation \\
\hline Norway & $\begin{array}{l}\text { Responsible designer, } \\
\text { builder and supervisor }\end{array}$ & $\begin{array}{l}\text { Recognition and supervision by the Norwegian Authority for Building } \\
\text { Quality }\end{array}$ \\
\hline Sweden & Private controller & Certification and supervision by Swedish Accreditation Authority \\
\hline
\end{tabular}

Source: Meijer and Visscher, 2016 
There can be a lot of confusion about the exact meaning and contents of the titles mentioned in Figure 3: "approved", "registered", "certified", "assigned" and "responsible". In general, registration is considered as the least restrictive form of (government) control, followed by certification, while licensing is the most restrictive (Jang and $\mathrm{Yu}, 2008$ ).

Besides the different designations, there are different forms of supervision on the controllers. It can be argued that supervision and control by governmental or accreditation bodies is preferable to control by professional organisations. This is because the first two types of control bodies are independent of the controllers. The research project did not look explicitly into the question what type of supervision works out best in practice. However, no practical evidence was found that one type of supervision works better than the other.

The supervision systems of all countries (except the new system in The Netherlands) set a series of requirements on the quality controllers. The height of the exact demands varies slightly between the countries. Sometimes, within a country, the requirements also differ depending on the scope the quality controller can get certified for. For instance, for the (structural) control of complex constructions, the demands on educational background and minimum years of practical experience are in some countries higher than for the control of less complex constructions.

As Figure 4 shows, the type of the demands on private quality controllers does not differ. They must have the following:

- a professional or academic degree (architects and engineers);

- practical experience which must be proven by statements, examples and/or an examination;

- proper professional liability or indemnity insurances; and

- an independent status. There may be no ties or relationships with other parties involved designing or building a construction that they control.

\begin{tabular}{|l|l|c|c|c|c|}
\hline \multirow{2}{*}{} & \multirow{2}{*}{ Quality controller } & \multicolumn{4}{|c|}{ Demands on: } \\
\cline { 3 - 6 } & & Education & Experience & Insurance & $\begin{array}{l}\text { Indepen- } \\
\text { dency }\end{array}$ \\
\hline England & Approved Inspectors & $\checkmark$ & $\checkmark$ & $\checkmark$ & $\checkmark$ \\
\hline France & Private control bureaus & $\checkmark$ & $\checkmark$ & $\checkmark$ & $\checkmark$ \\
\hline Germany & $\begin{array}{l}\text { Architects, engineers and } \\
\text { recognized experts }\end{array}$ & $\checkmark$ & $\checkmark$ & $\checkmark$ & $\checkmark$ \\
\hline Ireland & Assigned certifiers & $\checkmark$ & $\checkmark$ & $\checkmark$ & $\checkmark$ \\
\hline Netherlands & Quality control instrument & & & & \\
\hline Norway & $\begin{array}{l}\text { Responsible designer, builder } \\
\text { and supervisor }\end{array}$ & $\checkmark$ & $\checkmark$ & $\checkmark$ & $\checkmark$ \\
\hline Sweden & Private controller & $\checkmark$ & $\checkmark$ & $\checkmark$ & $\checkmark$ \\
\hline
\end{tabular}

Source: Meijer and Visscher, 2016a

Figure 4 . Demands on private controllers 


\section{IJLBE \\ 9,2}

\subsection{Builders}

There are hardly any recognition or certification schemes in place regulating the quality of builders. The building regulations in the countries studied also do not impose demands on the quality of builders. As far as the quality of builders is mentioned in the regulations, the demands usually are phrased in general and vague statements like: "Builders/installers have to comply with general rules concerning materials and workmanship and they must ensure that the work complies with all applicable requirements". What can be noticed is that practically all building regulatory documents refer to requirements related with the obligations to take on buildings defects insurances and insurance on professional liability. These demands are regulated outside the building regulations. In some countries, this is arranged in public law and in other countries in private law. This is an indirect way to guarantee construction quality. In case of failure, insurance money could become available to make the necessary repairs.

Some countries make - within the scope of building regulations - more direct demands on the quality of builders. This is primarily reflected in the requirements builders must fulfil when they want to act as quality controllers. The previous section shows that examples can be found in Norway and Sweden. In these countries, a builder has to be recognised or certified by a governmental or accreditation organisation to play a role in the quality control procedure. This means that the quality of the builder is checked. This applies to the operational management of the company (e.g. solvency and taxpaying ethic) and the educational and practical experience of those who are going to be responsible for the inspections (Meijer and Visscher, 2016).

Other countries impose quality demands on builders in a more straightforward manner. For instance, French building enterprises have to be registered to be eligible to take up insurances. A decisive factor behind this system is the French insurance and guarantee system for construction (Meijer and Visscher, 2016). The relevant law (Spinetta Law dating from 1978) dictates that every building professional involved with a construction project must have appropriate insurances. Builders and contractors have to be registered to meet this guarantee provision. This defines at least a minimum professional quality level of builders.

Ireland undertakes attempts to develop a registration system for builders: the Construction Industry Register Ireland. Only builders that deliver a minimum level of quality can be registered. At the moment, this register functions only on a voluntarily basis. Other countries (e.g. The Netherlands) consider the implementation of a web-based system, along the same lines as the Irish one.

A more concrete example of quality demands on builders inside the building regulatory framework is the Competent Person Scheme in England and Wales. Specialist installers can join this scheme specific for their line of business. If certified (depending on education and practical experiences), these installers can self-certify certain types of building work (e.g. glazing and heating systems). For these works, building regulations approval is not needed; it is assumed that the work meets the requirements. Such a system could be an interesting example for other countries because:

- It focusses on construction elements that are relevant for the quality of constructions. In this case, the energy performance (glazing, installations and insulation).

- It is incorporated in the Building Regulations and thus the quality control system. Work done by competent persons is considered to meet the minimum demands set in the regulations. 
- The system is regulated by certification schemes. Installers have to meet demands on education, experience and capabilities and they are being audited regularly.

The most important question is whether this system functions effectively in practice. Because of the purpose and design, this was not addressed in this research project. To conclude this section, it is apparent that besides demands on insurances, few demands are made on the quality of builders in Europe. Ideally, builders and installers should build constructions in a competent and skilful manner, so one could expect that the completed construction at least meets the minimum regulatory quality demands. The reality is, however, always more complex than the theory. The practice shows that builders make mistakes and sometimes deliver substandard work. In The Netherlands alone, the cost of failure rate in the construction industry in 2008 was calculated to be 11.4 per cent of the total turnover in that year (USP Marketing Consultancy, 2008). Estimations for Germany in 2016 came around an even more staggering 14 per cent of the total turnover (BauInfoConsult, 2016). There are no reasons to believe that the situation in the other European countries will be radically different. Future research is needed to get more insight into the relation between the size and causes of failure costs and the effectiveness of the quality control system. Could it be that the current control mechanisms are not adequate enough to recognise these failures during the construction and the quality control process? And if yes, what are the main causes for that (are the - private - inspectors inadequately equipped; are the demands on the control and inspection processes left much too open, etc.). At the moment, we do not know how strong the relation is between the two, but the high failure rate and costs are an indication for the imperfectness of the building industry and the apparent need to control it thoroughly. For that fact alone, it could be argued to increase both the quality demands on builders as the quality of building control. It could be the key ingredients to improve the outcome and reliability of the quality control systems.

\section{Conclusions and recommendations}

The current quality control framework of a country is the result of (and embedded in) decades of traditions, developments in governmental structures, regulations and the enforcement practices of a specific country. It is a unique system which makes it impossible to transfer a (apparently effective) system from one country to another. Insight is needed into the specifics and maturity of a regulatory system of a country to be able to understand and learn from the best practices, policy approaches and instruments of that country. In the field of national energy efficiency regulations in European countries, Annunziata et al. (2013) also used that principle to try to answer the research question how the design of the policy approaches and instruments could be strengthened and improved. Rather than focussing on the contents of the regulations, the recommendations below are mainly focussed on the question how the effectiveness and rate of compliance (enforcement) of the quality control framework can be enlarged. Research works done by Burby et al. (1998), Lord et al. (2016) and Meijer and Visscher (2016) show that effective building regulations need to be formulated into an unambiguous, strong and enforceable way. The enforcement process must be clear and carried out by qualified personnel. There should be serious penalties and consequences when regulations are not met. Effective regulations should be related with a level of deterrence that is high enough to prevent non-compliance.

\subsection{Formulation of the requirements}

As stated before, building regulations should be formulated into an unambiguous and enforceable way. This is strongly related with the way technical requirements are defined 


\section{IJLBE 9,2}

and formulated and the question if they are clearly interpretable or open to broader interpretation. Previous projects and publications (Sheridan et al., 2003, Visscher et al., 2005, Meacham, 2016) show that during the past decade(s), most countries have changed their prescriptive or functional requirements in a coherent and connected set of performancebased requirements. These requirements indicate the minimal performance of building component or composition of components. This means in theory that new design solutions and building methods are possible to reach the requirements and - in terms of Lord et al. (2016), they steer at output (the minimum performance) than on input. In practice, however, many countries provide the building industry with guidance's how these performances can be realised. Of the countries studied, the English Approved Documents are in this respect the most far-reaching solution. In other countries, however, most builders also use standard solutions that have proved themselves in practice. This means that builders steer on input rather than output, and this can hinder output-based inspection. A problem related with this: some quality aspects like energy use can actually only be inspected in a valid way after the building has been delivered. A more general observation is that quality control systems tend to focus heavily on newly built constructions. By far the biggest quality tasks such as for improving the energy performance of existing housing lie in the building stock that has already been built. New and coherent output-based regulation is necessary there too.

\subsection{Enforcement process}

A further important aspect of the quality control process is the way the enforcement procedures are defined (Lord et al., 2016). Is it clear when the quality control starts (design phase) and ends (at completion or also during the user phase)? Are control and inspection methods and procedures described, to what detail and is an inspection plan obligatory? The role and tasks of the inspectors and controllers is a second important item. Who are responsible for control and inspection, how competent are these controllers and are they supervised? What are the penalties for not complying and what is the power of inspectors or regulators to impose or apply these penalties? The research results indicate that the current enforcement frameworks seem to be adequate enough. Traditionally, public authorities in Europe were responsible to check whether constructions met the minimum quality demands set in the Building regulations. The applicant submitted his building plan; local authority building control checked it and when approved, a building permit was issued. During construction and at completion, the quality of the works was inspected, but emphasis was on the plan approval phase.

This situation has changed considerably. In a growing number of European countries, private building professionals have taken the lead in the quality control processes and statutory control procedures cover all phases of the construction process. The supervising role of private parties is limited to the technical requirements. Local authorities still take care of planning control issues.

Statutory control activities have been more evenly distributed over the building process. During the process, qualified architects (e.g. Germany, France and Ireland), qualified builders (e.g. Norway and France) and qualified controllers (all countries studied) are responsible for quality control. These specific building professionals that are qualified to control constructions must generally comply with obligatory demands on education, practical experience and insurances for building defects and professional indemnity. The research project did, however, not gather information about the way the private controllers are functioning in practice and the effectiveness of the way they are being supervised.

After the construction is completed, the inspection results have to de reported before a completion certificate is issued by the authorities. With these procedures in place, one could 
argue that chances are fair that a construction as built meets the intended technical minimum quality.

This research project focussed on the contents and organisation of the quality control procedures and not on the practical effects. The project did not generate an elaborate insight into the effectiveness of the quality control procedures in the various countries. This can be considered as a weakness of this study and it is - at the same time - an important recommendation for further research. This does not mean that nothing can be said about the adequateness of the current enforcement frameworks. On the basis of this study, recommendations can be made relating to both in the quality of the processes as the quality of the stakeholders involved.

First thing to notice is that the quality of many constructions is not or only partly controlled. The list of constructions that are exempt from control or just have to be notified to the building control authorities has grown significantly in the past few decades. Although these constructions are not or not completely controlled, they still have to meet the building regulations in the countries studied. In all countries studied, web applications exist that help applicants to determine whether their building plans are permit free or not. When a permit is needed, the applicant can submit his plan online in most countries. These internet applications do not guide an applicant further through the construction process. Governments are advised to develop these online tools further to guide applicants with a permit-free construction through the construction process. The Netherlands is in the process of developing such an online tool (Meijer and Visscher, 2016). Related to this, one has to face up to the fact that the majority of the consumers that are confronted with the quality control procedures for constructions are ordinary citizens. In The Netherlands, around 75 per cent of all permits are issued to non-professional applicants for relatively simple construction works. These applicants generally lack the knowledge and experience that building professionals have. An important question to take into consideration for future research is to what extent current regulatory systems are adequately geared towards the needs of these non-professionals.

Whether influenced by the growing privatisation of building control or not, it is clear that there has become more room for economic and insurance-based regulations. This has influenced the scope of quality control contents of constructions that are still eligible for control. The research has shown that the statutory demands in all countries focus on control of structural and fire safety issues of complex constructions. The underlying argumentation for this is related to risks of failures and insurance risks. This means that relatively little attention is paid to the control of sustainable requirements and more in general the control of simpler constructions (e.g. dwellings). Building regulations and their enforcement procedures cannot be based completely on insurances systems (e.g. the French system) because the goals of building regulations are not exclusively focussed on minimising risks or accidents. Important quality issues like sustainability, energy performance, usability and accessibility that do not relate to risks, and assurances also need to be controlled properly. At the moment, the enforcement of these themes is insufficiently regulated. There must be more balance between the statutory demands on all the issues regulated in the building regulations. This applies especially with respect to inspection and control. Although most countries studied demand an inspection plan (France, Ireland, The Netherlands, Norway and Sweden), the regulations hardly contain obligatory demands on the frequency and intensity of site inspections or on control and inspection methods. To realise a proper and adequate control of constructions, the countries studied should be clearer in their regulations about the control and inspection methods that could or must be used by the quality controllers. Exceptions - on a limited scale - can currently be found in France and Norway. In the 
IJLBE 9,2

proposed new quality control system in The Netherlands, inspection and control methods play a key role.

This project did not study the level of deterrence or the height of the penalties in the various countries. In future research, it would be interesting to relate, for instance, the height of the failure costs in a country with the height of the penalties of non-compliance. It could possibly give an indication of the possible relationship between of non-compliance and the level of deterrence. In general, safety risks are covered by limited insurance schemes. The proposed new system in The Netherlands foresees a greater liability for builders to protect the consumers. A builder will also become liable for defects that occur after the construction has been delivered.

\subsection{The regulated sector: builders}

The building sector usually complains that building regulations put a heavy administrative and financial burden on them. Making regulations stricter will make this burden even higher. It is necessary to acknowledge that a regulatory system costs money but that it also brings benefits. The upholding of an adequate quality control system involves indeed a heavy financial burden, but could at the same time generate substantial savings by preventing large-scale failure and repair costs. As precise insights into the relation between these two is lacking, it would be worthwhile in further research to get a better insight into these costs and potential savings. What also should be acknowledged is the fact that building regulations and its enforcement system function as a safety net to guard a socially acceptable minimum level of quality. If the regulees involved at the supply side deliver this quality, enforcement could be less intensive and less expensive. In this light, it makes sense to improve and stimulate the quality level at the supply side. This could be realised by setting quality demands on builders, but also by trying to improve the cooperation between regulators and builders by advocating the importance of quality.

In terms of setting quality demands, there are some promising developments (like emerging certification and registration schemes); however, concrete demands on the quality of builders and installers (e.g. concerning their responsibilities and liabilities) to make it surer they deliver safe and sound constructions are yet to be made in most European countries. Making more statutory demands on the quality of the work done by builders could be a next consideration. These demands should not only be based on possible failures within the boundaries of their insurance and indemnity insurances schemes but also on the overall goal to build quality sound constructions. This could be partly realised through more training and more funding for construction quality within the building industry. Selfregulation by umbrella organisations of building professionals, e.g. via certification or registration schemes, would appear to be an appropriate solution. After all, realising constructions with a good quality is also in the interest of the building industry.

With respect to the second solution (creating awareness and/or cooperating with the regulees), Burby et al. (1998) pointed out that regulators face two critical choices when they want to improve compliance. The first choice is to focus on making the enforcement system stricter to detect and correct violations, or to focus on building commitment among builders and developers so they will comply with regulations without the need for intervention by the enforcers. The second choice is whether to foster such commitment by emphasising strict enforcement of regulations, or by facilitating compliance by working cooperatively with regulated builders and applicants to induce them to comply. Burby's findings support the efficacy of fostering regulated entities' commitment to comply, and of facilitating willingness to comply among builders. This is not limited to individual builders. In her study on the effectiveness of building codes in the USA in the face of climate change, 
Shapiro (2016) advocates useful new concepts ("participating, pricing and policing”), to come to better and effective regulations to moderate the effects of climate change. These concepts are also worthwhile for the wider building quality theme. All countries already have established organisations and platforms that discuss building regulations regularly. Within these existing structures, policymakers especially must become even more engaged together in code advocacy.

\subsection{Concluding observations}

In further research, it would be interesting to look at the quality control of constructions from a broader perspective. Building regulations in general are of an inflexible character. They are often the result of political compromise and they steer at minimum quality levels. While analysing specific US regulations to tackle climate change, Eisenberg (2016) argues that the regulatory role should not be limited to guarding minimum arbitrary boundaries between what is legal or not. Eisenberg (2016) makes an appeal to explore alternative avenues to create comprehensive and effective regulatory systems. In the field of housing quality, countries have besides regulatory tools, other incentives and instruments aimed at improving construction quality. This varies from quality demands related to home insurances to quality levels set in warranty or hallmark policies. Attempts could be made to integrate and connect the various quality demands within a wider governance scheme that generates the most regenerative and positive outcomes. This also implies that proper and structural monitoring of the efficiency and effectiveness policy and other instruments is necessary. Although "building regulatory organisations" are active in all countries that focus on the contents of the requirements and the way building control should take place, a coherent and evaluative approach to look at the effectiveness and efficiency of the requirements could still be developed further. Only when accidents and incidents happen with constructions (e.g. as has happened in The Netherlands and Germany during the past decades), the political attention focusses on the regulations and responsibilities of parties involved.

The arrangement of an effective quality control system is a complicated puzzle. However, the puzzle can be solved in different ways. When the right pieces are brought together, the effectiveness of the quality control procedure and the commitment of builders to comply can be enhanced. The main pieces to lay together an effective quality control system of constructions have been discussed in this section. The regulations should be formulated into an unambiguous and enforceable way. The regulations set out the enforcement process (with a clear start and ending). During construction, an inspection plan that has been drawn up in advance must be followed. The inspection should encompasses all the issues that are regulated. The control and inspection methods must be clear. After the end inspection, a completion certificate is issued that gives a reflection of the quality control process. The quality controllers should be up for their tasks. They must have sufficient training and the right qualifications and they must have powers to act in cases of non-compliance. There should be serious penalties and consequences when regulations are not met. This quality control process is a safety net, and builders and other regulees must also be stimulated to deliver quality. This can be realised in various ways. Umbrella organisations within the building industry could be stimulated to introduce quality systems or certification schemes to stimulate quality care within the building industry. The liability for builders in cases of failures can be enhanced. Reliable benchmark systems can be set up for customers to assess the quality of builders. This paper has made some recommendations aimed at both the regulators as the regulees that could be used to help to solve the complicated puzzle. 


\section{IJLBE \\ 9,2}

\section{References}

Annunziata, E., Frey, M. and Rizzim, F. (2013), “Towards nearly zero-energy buildings: the state-of-art of national regulations in Europe", Energy, Vol. 57, pp. 125-133.

BauInfoConsult (2016), "Fehlerkosten am deutschen Bau nähern sich Rekordniveau: 14,1 Milliarden €in 2015", Failure cost in German Construction Approach Record Level: €14,1 Billion in 2015, BauInfoConsult GmbH, Düsseldorf, available at: www.bauinfoconsult.de (accessed 15 December 2016).

Beerepoot, M. (2007), "Energy policy instruments and technical change in the residential building sector", Thesis Delft University of Technology, Delft.

Berge, O.Ø. (2003), "Building control in Norway and the Norwegian regulatory system", National Office of Building Technology and Administration, IBCI, Bengaluru.

Burby, R., May, P.J. and Paterson, R.C. (1998), "Improving compliance with regulations: choices and outcomes for local government", Journal of the American Planning Association, Vol. 64 No. 3, pp. 324-334.

Costa Branco, J., Meijer, F. and Visscher, H.J. (2011), "Comparison of building permit procedures in European Union countries", in Chynoweth, L.R.P. (Ed.), COBRA 2011, RICS Construction and Property Conference, RICS \& University of Salford, Salford, pp. 356-375.

DCLG Department for Communities and Local Government (2014), Building Control Performance Standards, London.

DECLG Department of the Environment, Community and Local Government (2014), Code of Practice for Inspecting and Certifying Building and Works, DECLG, Dublin.

Deman, J. (2013), Building Control Systems and Technical Control Activities in Belgium, Técnico Lisboa, Lisboa.

DiBK Direktoratet for ByggKvalitet (2016), "Norwegian authority for building quality", available at: www.dibk.no/ (accessed 29 November 2016).

Ecorys and Delft University of Technology (2016), Simplification and Mutual Recognition in the Construction Sector Under the Services Directive (Markt/2014/087/E) Final Report, ISBN: 97892-79-51535-4.

Eisenberg, D.A. (2016), "Transforming building regulatory systems to address climate change", Building Research \& Information Special Issue on Building Governance and Climate Change: Regulation and Related Policies, Vol. 44 Nos 5/6, pp. 468-473.

IBK Instituut voor Bouwkwaliteit/Institute for Building Quality (2014), "Rapportage Verkenningsfase; op weg naar een toelatingsorganisatie", Reconnaissance Report; On The Road Towards an Admittance Organisation, The Hague.

Imrie, R. and Street, E. (2009), "Regulating design: the practices of architecture, governance and control", In Urban Studies, Vol. 46 No. 12, pp. 2507-2518.

Imrie, R. and Street, E. (2011), Architectural Design and Regulation, Wiley-Blackwell, Chichester.

Jang, S. and Yu, F. (2008), "The triad of credentialing processes in engineer quality regulation: accreditation, certification and licensure/registration", PICMET 2008 Proceedings, Cabe Town. IEEE, 27-31 Julv.

KoRD Kommunal og Regionaldepartemente/Ministry of Local Government and Regional Development, Housing and building department (2010), Regulations Relating to Building Applications, KoRD, Oslo, 26 March.

Lord, S.F., Noye, S., Ure, J., Tennant, M.G. and Fisk, D.J. (2016), "Comparative review of building commissioning regulation: a quality perspective", Building Research \& Information, Vol. 44 Nos 5/6, pp. 630-643.

MBZK Ministerie van Binnenlandse Zaken en Koninkrijksrelaties/Ministry of Interior and Kingdom Relations (2015), "Ontwerp wetsvoorstel kwaliteitsborging voor het bouwen”, Bill on Quality Control for Construction Works, MBZK, The Hague. 
Meacham, B.J. (2016), "Sustainability and resiliency objectives in performance building regulations", Building Research \& Information Special Issue on Building Governance and Climate Change: Regulation and Related Policies, Vol. 44 Nos 5/6, pp. 474-489.

Meijer, F.M. and Visscher, H.J. (1998), "The deregulation of building controls: a comparison of dutch and other European systems", Environment and Planning B: Planning and Design, Vol. 25 No. 4, pp. 617-629, Pion, London.

Meijer, F.M. and Visscher, H.J. (2006), "Deregulation and privatisation of European building-control systems", Environment and Planning B: Planning and Design, Vol. 33 No. 4, pp. 491-501.

Meijer, F. and Visscher, H. (2016), "QuickScan van buitenlandse stelsels van kwaliteitsborging in Engeland, Ierland, Duitsland, Frankrijk, Noorwegen, Zweden en Australië", Quick Scan of Quality Control Systems for Building in Germany, England \& Wales, France, Ireland, Norway, Sweden and Australia, Delft University of Technology, Delft.

MLHD Ministère du Logement et de l'Habitat Durable (2016) "Ministry of housing and sustainable environment", available at: www.territoires.gouv.fr/ministere (accessed 24 September 2016).

Rosenow, J., Fawcett, T., Eyre, N. and Oikonomou, V. (2016), "Energy efficiency and the policy mix", Building Research \& Information. Special Issue on Building Governance and Climate Change: Regulation and Related Policies, Vol. 44 Nos 5/6, pp. 562-574.

Shapiro, S. (2016), "The realpolitik of building codes: overcoming practical limitations to climate resilience", Building Research \& Information Special Issue on Building Governance and Climate Change: Regulation and Related Policies, Vol. 44 Nos 5/6, pp. 490-506.

Sheridan, L., Visscher, H.J. and Meijer, F.M. (2003), "Building regulations in Europe part II", A Comparison of Technical Requirements in Eight European Countries, Housing and Urban Policy Studies 24, Delft University Press, Delft.

USP Marketing Consultancy (2008), "Faalkosten in de bouw naar hoogtepunt", Geschatte Verspilling in 2007: €6,2 Miljard (Failure Costs in Construction to a New Height; Estimated Waste in 2007: €6,2 billion), USP Marketing Consultancy, Rotterdam.

Visscher, H.J., Sheridan, L. and Meijer, F.M. (2005), "The formulation of building regulations in eight European countries", Building Research Journal, Vol. 53 No. 4, pp. 193-205.

Visscher, H., Meijer, F., Majcen, D. and Itard, L. (2016), "Improved governance for energy efficiency in housing", Building Research and Information: The International Iournal of Research. Development and Demonstration, Vol. 44 Nos 5/6, pp. 552-561.

World Bank Group (2013), Investment Climate; Good Practices for Construction Regulation and Enforcement Reform (Guidelines for Reformers), Washington, DC.

\section{Further reading}

Meijer, F.M., Visscher, H.J. and Sheridan, L. (2002), "Building regulations in Europe, part I: a comparison of systems of building control in eight European countries", Housing and Urban Policy Studies, Vol. 23, Delft University Press, Delft.

\section{Corresponding author}

Frits Meijer can be contacted at: f.m.meijer@tudelft.nl

For instructions on how to order reprints of this article, please visit our website:

www.emeraldgrouppublishing.com/licensing/reprints.htm

Or contact us for further details: permissions@emeraldinsight.com 